Open Access

\title{
Discipline and distinction in the age of the Internet: a sociological study of the fitness practice
}

\author{
Jun Tang ${ }^{*}$ and Zilong Xie
}

\author{
* Correspondence: tangjun@bjut. \\ edu.cn \\ Beijing University of Technology, \\ 100 Pingleyuan, Chaoyang District, \\ Beijing, People's Republic of China
}

\begin{abstract}
This article examines popular fitness sports and home fitness software in China. Drawing on Michel Foucault's theory of discipline, Norbert Elias' study on civilization, and Jean Baudrillard's study on the consumer society, the authors reveal the formation of a new body discipline mechanism against the background of the Internet society and the consumer society. On the one hand, the external disciplinary strategies have been upgraded, including the spatial strategy of liquidity and visibility, the linear and rhythmic time strategy, and the knowledge strategy. On the other hand, different from Foucault's discussion of discipline, we introduce positive self-discipline. As a unique consumption practice, fitness practices promote a new form of self-discipline among practitioners who also pursue distinctive social positions. The core content of the self-discipline strategy includes code manipulation, time consumption, moral display, and self-writing. In addition, with the continuous infiltration of Internet technologies in daily life, the space-time boundaries of physical discipline gradually blur, whereas the micro-distribution of power changes into a daily distribution form.
\end{abstract}

Keywords: Discipline, Distinction, Fitness, Internet

\section{Introduction}

In the narrow sense, fitness refers to a type of exercise that includes strength training and aerobic exercise, aiming to reduce fat, grow muscle, and shape the body. It began in the West and was imported into the Chinese mainland in the early twentieth century (Xu 2013), but fitness gained popularity until recently.

If we put aside the difference between fitness sports and physical sports in a general sense and start from the fact that modern sports in China began following the national crisis that occurred in the late Qing Dynasty, the development of sports in China has had a rather clear political imprint from the very beginning. In the early modern Chinese schools, the various ways of shaping students' bodies through sports contained the strong idea of "the nationalization of the body" (Shao 2014). After the founding of the People's Republic of China in 1949, the promotion of sports was also closely related to the improvement of people's physique and ultimately linked with the strength of the

(c) The Author(s). 2021 Open Access This article is licensed under a Creative Commons Attribution 4.0 International License, which permits use, sharing, adaptation, distribution and reproduction in any medium or format, as long as you give appropriate credit to the original author(s) and the source, provide a link to the Creative Commons licence, and indicate if changes were made. The images or other third party material in this article are included in the article's Creative Commons licence, unless indicated otherwise in a credit line to the material. If material is not included in the article's Creative Commons licence and your intended use is not permitted by statutory regulation or exceeds the permitted use, you will need to obtain permission directly from the copyright holder. To view a copy of this licence, visit http://creativecommons.org/licenses/by/4.0/. 
ethnic group and the country's power. This was also implied in Mao Zedong's inscription for the launch conference of the China Sports Federation on June 10, 1952-"developing sports and strengthening people's physique." Since the reform and opening-up in the 1980s, the state has reduced its intervention in sports and has gradually transformed its policies from intervention to guidance. As a result, the Regulations on National Fitness (2009, 2016), the National Fitness Program (2016-2020), and other relevant policies have been issued. The reason for this policy transformation is that the market economy and instrumental rationality has gradually replaced the role of state authority and value rationality in people's daily life. A series of political symbols attached to the body, such as revolution, sacredness, sublimity, and greatness, have been dispelled. Thus, the body has been assigned secular life (Zhao 2010). The return of viewing the body as secular instead of sacred is embodied in the sports field, where fitness sports emerge and develop as public sports and leisure activities.

Since the late 1990s, Chinese passion for sports, including fitness sports, had been greatly ignited by the "advanced lifestyle" labeled based on the foreign fitness culture and boosted by the marketing campaigns of sports products and events such as the 2008 Beijing Olympic Games and the 2022 Beijing Winter Olympic Games. The consensus that a person should have a "good figure for clothing" and a "nice body, good temperament, and great charm" has been crystallized. The driving force of fitness participation has gradually shifted from the outside to the inside. Under the social background of class stratification, fitness also seems to have become the middle class and elite groups' lifestyle and identity. Consciously or unconsciously, actively or passively, people participate in and even obsess over fitness sports, which is a new phenomenon beyond the scope of the existing sports research, fitness research, or the traditional body research.

It is worth noting that the rapid development of the mobile Internet is fueling the current fitness trend. The birth of fitness application (app) for mobile phones has helped the traditional offline fitness industry transform into the online industry to achieve unprecedented development while meeting users' needs. Keep is one representative of the more successful apps. ${ }^{1}$ If the sports policy's transformation indicated the weakening of the state's direct supervision of people's fitness activities, the emerging fitness software took the fitness trainer's position in daily life. The fitness venue has expanded from the gym to daily living spaces. Under the background of such changes, people's passion for fitness has not subsided; instead, it has increased, which has not been widely discussed in the existing research on the body, especially the research on discipline. Therefore, by analyzing fitness sports and using Keep as the starting point and the case, this paper attempts to answer the following questions: first, given the rapid changes in technology and the Lack of traditional supervised teaching methods, does the discipline mechanism still exist in the fitness practice, and what changes have taken place? Second, can the remarkable passion for unwavering identification and considerable investment into fitness be explained by internal self-discipline? If the answer was yes, what type of self-discipline is this? Finally, can we infer that the mobile

${ }^{1}$ According to Keep's official report, the app development company has completed five rounds of financing, including Angel investments, in the 2 years and 7 months since the launching of the app on February 4, 2015. Keep currently has 100 million registered users and 30 million monthly active users. 
Internet technology in the information age has boosted the construction of new power distribution?

\section{Background and literature}

Fitness was imported into China at the beginning of the twentieth century. It was closely related to the attention intellectuals gave to the body in their pursuit of saving the nation and the future. As (Huang 2006:42) pointed out, in the late nineteenth century and the early twentieth century, the late Qing dynasty and ordinary Chinese shared a view that the transformation of the body was the basis of the transformation of the country. In the field of sports, various western sports courses and projects were introduced. In the early 1930s, Zhuguang Zhao, the father of the Chinese fitness movement, and other precursors founded the first fitness association in China-the Bodybuilding Association of Hujiang University-to transform "the weak country and feeble people." They translated foreign fitness books to promote fitness sports among common people and called for self-improvement through fitness sports (Zhao 2015). Unfortunately, after the founding of socialist China in 1949, fitness sports were regarded as bourgeois sports and were halted until the reform and opening-up of the 1980s (Zhao 2015). In recent years, due to the popularity of fitness sports, many entrepreneurs searching for investment opportunities pour capital into the fitness industry. In this context, fitness apps attracted the attention of researchers.

To explore the issues of fitness or sports, we need to mention that sociologists had ignored the body for a long time. If the political and economic significance of the body was recognized with the development of biology, economics, and other disciplines after the industrial revolution, its social significance did not draw sociologists' attention until the 1980s, when population aging, the feminist movement, and consumerization of the body became prominent (Browning et al. 2004:529-530). This is the so-called "body turn" in sociology.

As one of the important promoters of "the body turn," Foucault adopted Nietzsche's genealogical methods and used the body as the reference to review the history of human beings. He found that the history of the body was a history of discipline and oppression. The means of discipline was not violence but a series of delicate physical techniques. This "body technique" concept came from Mauss, who believed that a person's life is the process of self-presentation and communication with others using various body techniques obtained through training. These techniques included learning to walk in childhood, etiquette training for women in adolescence, running, dancing, and driving in adulthood (Mauss 2004:301; Wen 2006; Lin 2013). Inspired by Mauss, Foucault developed his analysis of power techniques. He believed that through space distribution, coding activities, hierarchical monitoring, and other strategies, the power of discipline produced a "tame body" to meet the different requirements in each production node in society.

The power of discipline has been expanding its scope and spreading from prison to society as a whole, which, since its birth, has affected the production of knowledge in schools and health in hospitals. As one of the important forms of physical, social practice, sports have naturally become an appropriate arena for discipline power. As we know, sports are not a type of go-as-you-please activity but are restricted by certain rules and norms (Meng 2011). Meanwhile, in the process of teaching sports, there is 
often a status gap between teachers and students. Teachers can regulate their students, who are often uninformed, by enacting a series of demonstrations and requirements. This long-term accumulation of actions ultimately generates "discipline with code marks" for the students (Gao and Li 2013). The research on sports culture, building on Foucault's work, aims to explain the power fluctuation between the growth of modern knowledge and the body commandments (Xiong and Zhang 2011), and they can be roughly divided into two groups. On the one hand, some scholars assert that sports produce and regulate the so-called "athletic body," which is regarded as a special body type that symbolizes health, strength, discipline, and productivity (Cole and Orlie 1995). Therefore, the sport is regarded as a representative of modern disciplinary power. On the other hand, some scholars criticized the alienation and distortion of the modern scientific discourse on the human body. They believed that it is the medical expression of the human body's biological nature that made normal physical exercise an appendage of the modern technical discourse system and an objection of oppression (Pronger 1995). The methods and standards of training have imposed a set of strict norms.

The discourse system (such as biology and sports science), teaching mode, and teaching method of fitness sports are similar to those of other sports. Therefore, fitness sports inevitably become a field of power discipline. Through interviews and observations, some scholars have exposed the training mechanism used in the gym and have suggested that the gym, with various standardized leverages, open spaces, and fitness coaches as supervisors, imposed concentrated discipline on the body (Zhong 2009). It is necessary to point out that the existing research on the discipline mechanism directly inherited Foucault's theory, either in the analysis of medical institutions, such as addiction treatment centers (Chen 2012), the investigation of schools (Tang 2016), or in the research on gyms (Zhong 2009). In other words, the discipline strategies conceptualized by Foucault have been found in subsequent studies, such as forming a relatively closed space, fixing the schedule, and grouping members. This leads to the first question of this article. As fitness sports have shifted from the gym to everyday life spaces, fitness sports are no longer performed in open spaces, there are no coaches or other supervisors, and users choose their courses or build social networks through apps by themselves. In this context, does the previous discipline mechanism still exist? If so, has it changed?

It is reasonable to say that in Discipline and Punishment, Foucault paid more attention to the analysis of various external discipline strategies, and the discipline he addressed was mainly related to mandatory institutional design. Although Foucault pointed out in his description of "panopticon" that the prisoners lived in a state of tension for such a long time that they would gradually internalize the external discipline and self-monitor because they did not know when and where they would be monitored (Foucault 2003: 225-227), this kind of monitoring was not real self-discipline. In this study, the author uses the word "self-discipline" to illustrate the phenomenon, that is, when no external coercion exists, the actors actively accept and learn about the body's normative discourse out of a positive will to do so. The users of fitness apps are a typical example. On the Keep platform, people who exercise regularly often regard fitness as a sport and view it as an important way of life. How can their strong belief and unprecedented investment in fitness be explained? This is the second question of this 
article: what motivates people who proactively learn about sports, record the time spent exercising, and even feel guilty if they were absent from working out?

In fact, the emergence of public sports, including fitness sports, first depends on the rise of the consumer society. With excess leisure time and consumption, ordinary people can engage in sports, tourism, and other cultural leisure activities. In the public choosing leisure activities, mass media plays an imperceptible but significant guiding role, in which health, beauty, and happiness are undoubtedly the most frequently used terms. (Beck and Beck 2011:161) argued that physical health maintenance had become a critical part of life in an individualizing society. To become outstanding in the competitive labor market, a person has to maintain a healthy body. Meanwhile, in the past 20 years, the development of preventive medicine has established a relatively wide connection between physical exercise and disease prevention (Zhao 2016). In other words, the patients can no longer complain about having bad luck, as in the past. They must thoroughly reflect on their everyday habits, such as their schedule, sports activities, and diet, and take the responsibility of "taking care of yourself." Fitness is becoming an important daily health management strategy, which people are increasingly acknowledging.

In addition to health, modern society is also committed to maintaining beauty. Similar to health, due to the development of science and technology, everyone must maintain "beauty." The emergence of various skincare products, physiotherapeutic instruments, and microplastic surgery provides ordinary people the possibility to obtain the "perfect face" described by the mass media. The assessment standard of "facial attractiveness" is further expanded and relates to the face and involves the figure. Therefore, fitness sports and cosmetics become a vital means to fulfill "the duty of becoming beautiful." In Guy Ernest Dobord's analysis of the society of the spectacle, capitalists generate a large number of symbolic images using media and advertisements, while consumers are addicted to the spectacle of symbols and become "the silent majority" (Zhang 2009). People who exercise are guided by "the ideal body image" perpetrated by the mass media become dissatisfied with their own body and then generate the intention to engage in fitness sports. Through working out, people have bravely shouldered the responsibility of maintaining that body image and eliminating the opposite effects of modern society from the body, such as aging, obesity, and illness.

Besides the pressure applied by the mass media to push people to the gym, fitness sports may be a means of self-presentation, helping individuals overcome their sense of insecurity, especially the potential gender insecurities in modern society. In contemporary workplaces, the expansion of non-manual work and the rise of the office culture have weakened the value of the muscles in production practice and have cultivated many frail white-collar men. Therefore, to resist the "invasion" of effeminacy, increasing numbers of men attempt to build the muscles as a way to demonstrate their masculinity (Turese 1999). Similarly, women are motivated to use fitness sports to deconstruct the male hegemony in the field of the body. Through their muscular body, females who exercise challenge the traditional definition of the female body as frail and self-limiting (Bunsell 2013: 11-12). Some other scholars try to analyze the motivation of the fitness community as a whole. Many people regard fitness sport as a subcultural phenomenon derived from low self-esteem and a sense of insecurity. Individuals display their strength to the outside world to compensate for their relatively low self-evaluation, 
especially for those who have been bullied, humiliated, or have obvious physical defects. The sense of insecurity that people who exercise feel is also embodied in their distrust of the external world and interpersonal relationships.

The individualized characteristics of fitness sports are thus meeting those special psychological needs. As a solid fortress, the strong muscles provide a safe and independent spatial imagination for individuals (Sault 1994: 82-87; Wolke and Sapouna 2008). In summary, though the practical value of physical strength in the social division of labor is the same as before, fitness sports not only bring about the obvious improvement of physical strength but also inject a strong psychological power into individuals to alleviate their sense of insecurity and anxiety caused by gender insecurity, physiological defects, trauma experiences, or communication disorders.

Unlike the discussion above, Glassner (1989) believes that fitness sports' success can only be fully comprehended when it is regarded as a postmodern cultural phenomenon. Taking "working out for health" as an example, the emergence of so-called preventive medicine exposes the limitations of the traditional clinical medicine system. People start to realize that they cannot rely on drugs to prevent death. Most patients suffering from heart attacks die before receiving any medical assistance. As a result, fitness sports in Western society have been adopted to liberate people from the disappointing medical institutions and the common, stressful, and sedentary lifestyle in modern society. Meanwhile, regarding "the aesthetic experience of fitness sports," we are still confined to the set pattern of modernity if we only focus on the beauty of the geometry and form of the anatomy. The production of fitness sports videos ought to be an example. It often takes several days to shoot one single course. Viewpoint correction, background music, and other video production details require a great deal of postprocessing. Even the so-called "class" is a combination of separate recordings. Therefore, rather than "the image is a copy of the real," "the real comes from a copy of the image." The fitness equipment is nothing more than pure simulacra. People who truly love rowing do not like the rowing machine; ${ }^{2}$ the spinning bike ${ }^{3}$ is nothing like the real bike. Hence, the rise of modern fitness sports echoes Jean Baudrillard's argument regarding the arrival of a so-called simulacrum society.

Glassner also pointed out that fitness sports, as a postmodern cultural practice, obscures many dualistic categories inherited from modernity, such as the self and the body, the inner and the outer, and male and female. Mead's distinction between the self and the body begins to blur in fitness practice due to the mass media's excessive use of body images. In the constant comparison between the body and images in the media, people gradually equate the body with the self and, consequently, explore the self by shaping the body. To save medical expenses and improve their corporate images, many large companies have built valuable fitness facilities for their employees, which further prompt people to pay attention to the body's transformation. The unification of the self and the body can also be understood as the gradual integration of the outer body's brilliance and the physical and mental health of the inner body. Given that in modern society, the various means of obtaining beauty, such as cosmetics and clothing, have

\footnotetext{
${ }^{2}$ The rowing machine is a kind of fitness equipment which simulates the water rowing for the purpose of training. It can significantly strengthen the muscles of the legs, waist, upper limbs, chest, and back.

${ }^{3}$ The spinning bike was first invented by American personal trainer and extreme athlete Jonathan Goldberg in the 1980s. It is a unique indoor exercise bicycle that combines music and visual effects.
} 
nothing to do with inner body health and even draw criticism regarding the vanity of the user, fitness sports aiming to directly transform the body bring the inner body and the outer body into harmony, in which changes in the outer body are also beneficial to the inner body. The distinction between men and women also becomes increasingly blurred in the field of contemporary fitness sports. Both men and women enter the gym for the same fitness goals and employ the same means to transform the body and eat the same dietary fitness supplements. People would even enter a trance-like state when browsing the photos of men and women who have obtained certain fitness achievements because the gender distinction seems to have disappeared in those photos. Some scholars (Obel 1996) regard it as a positive phenomenon and believe that the refusal of fitness sports to adhere to traditional gender classification complicates and blurs gender identification, which is conducive to the development of a new identity.

In summary, fitness sports have many characteristics of postmodernism, especially in eliminating and blending many of the dualistic categories in modernity. After all, fitness sports are a product of modernity. Neither the hegemony of the technical discourse of fitness experts nor the unidirectional information collection of operators can eclipse the power issue in the fitness practice and the imbalance between the subject and object of physical discipline.

The characteristics of the academic discussion of fitness sports can be summarized based on the literature review. First, fitness sports and sports (fitness in a broad sense) are often discussed as one issue. In this sense, the research object is too broad to generate a specific analysis of fitness sports. Second, most existing literature focuses on the issue of gender discipline in fitness sports from the perspective of feminism and discipline theory (Chen and Min 2014; Xiong 2013; Wan 2015). However, the many discussions about gender discipline have neglected, if not replaced, exploring the general mechanism of fitness discipline. Finally, for the motive for engaging in a fitness practice, the self-presentation explanation is mostly applicable to specific groups, such as different groups of people divided by gender or people who have experienced specific psychological traumas and those with specific needs. The rest of the research mainly explains the fitness phenomenon from the perspective of mass media symbol production, which also has limitations. In either the pursuit of health or beauty, engaging in fitness sports is not the only way. So, how does fitness stand out or even create a booming physical exercise trend? It is worth an in-depth and detailed explanation of the internal dynamic mechanism of why people exercise. Therefore, this paper attempts to generate a more in-depth analysis of the external discipline strategy of fitness sports and the internal dynamic mechanism of the selfdiscipline of people who exercise in the era of the Internet by investigating popular fitness sports and the domestic fitness app, Keep.

\section{Upgrade of external disciplinary strategies}

The discussion of the newly emerged fitness app may encounter some challenges; for most people who exercise, many types of professional fitness equipment can only be found in the gym, so would the role of app in fitness be overestimated? It is not difficult to observe by browsing the current popular fitness app solutions that most courses 
provided by various apps are bare-handed training ${ }^{4}$ and simple equipment exercise ${ }^{5}$, which are the types of fitness sports that rely little on the venue and the equipment. According to the annual global fitness trend prediction ranking released by the American College of Sports Medicine (ACSM), bare-handed training ranked second among many training projects in 2016 and 2017, second only to wearable technology. People increasingly welcome Bare-handed training and simple equipment exercises because of their simplicity and practicality advantages, which play increasingly important roles in the body shaping process. Based on this fact, we can perform the following analysis with more confidence.

\section{Spatial strategy: liquidity and visibility}

In Foucault's analysis of power, space is a crucial category, which illustrates "the relationship between power and knowledge" (Foucault 1997:205). Building a mental hospital to separate the normal from the abnormal and taming violence through a panopticon is essentially a strategy for the reproduction of spatial power, whose reproduction process increasingly needs the guidance of knowledge. Therefore, with the development of Internet technology, the spatial strategy of discipline has also undergone new adjustments to become more invisible and efficient. In the fitness field built by Keep with the Internet's help, the new spatial strategy is characterized by two features-liquidity and visibility.

In Foucault's analysis, the space of discipline is often closed. After all, only by ensuring that patients stay in the ward and students stay in the classroom can the discipline of the body be carried out. However, for the users of fitness software, the exercise venue becomes more flexible. Fitness sports can be carried out at any time in the bedroom, at work, or in the park. The closeness of the space is thus a challenge. Does the rising of liquidity and visibility break the shackles of power or constitute a new spatial strategy?

The closure has never been the ultimate pursuit of the spatial strategy. "The principle of closure is not eternal in the discipline mechanism...This mechanism makes use of space in a more flexible and detailed way. It is based on the principle of unit location and segmentation. Each person has his own position, and each position has a person" (Foucault 2003:162). Therefore, rather than that the discipline needs a closed space, people at that time emphasize the closure of space to supervise the growing population better and avoid the possible disorder caused by the population flow because they did not master the technology of "locating individuals" in open spaces. However, with the development of Internet technology, it becomes very simple to locate individuals. When installing the Keep, the app asks the user "whether to open the permission of geographic location." Once the user clicks agree, the user's spatial location and tracking will be monitored by the software. Based on the user's geographic information, Keep will provide various LBS functions (location-based service). For example, the "hot sports" function shows nearby hot fitness sites to help people meet offline or recommends people with common demands in the same city to establish contact. With the

\footnotetext{
${ }^{4}$ Bare-handed training refers to the method of body building that uses only the body and gravity, without using equipment.

${ }^{5}$ Simple equipment exercise refers to the method of body building that uses dumbbells, elastic bands, and other simple equipment.
} 
popularization of mobile services and the further fragmentation of everyday life, the liquidity of the subjective practice becomes increasingly active; the construction and reorganization of spatial relations imply a trend of liquidity (Liu 2014). However, it is paradoxical that discipline does not fail with increased spatial liquidity. Instead, with individuals' mobility, the discipline arrives at people's private lives, which can be proved by official investigation reports. ${ }^{6}$ What was originally conducted in the gym is now duplicated in fragmented spaces, such as bedrooms, offices, and parks, which infinitely extends the space for discipline, subsequently builds a connection between individuals and continues to reconstruct the spatial relationship in the everyday lives of people who exercise.

The visibility of space is closely related to the liquidity of space. The technology of "locating individuals" is essentially a type of gaze, browsing users' geographic information and spatial relations. However, if it were only functioning in this way, it would not go beyond the unidirectional supervision mechanism of watching and being watched in the panopticon (Foucault 2003: 225-227). In fact, the pattern, function, and significance of a "gaze" have changed fundamentally. To be specific, the former panopticon, in which a few people watch most people, has changed to the omnipticon, in which most people watch most people (Rosen 2005:11) and the synopticon in which most people watch a few people (Mathiesen 1997). The influence of power on "spatial visibility" has entered a new stage.

In the "omnipticon," as we observe in various social media, people are tirelessly updating their status, over-sharing their position, behavior, mood, and even all private topics. While watching others, people instinctively adjust their own network status under the pressure of being watched by others (Liu 2014). Keep has a section that is similar to a "community." Users can browse each other's fitness status, which may be a photo of a sweaty body or an encouraging motto. The power of "watching" is transferred from the guards in the panopticon to every ordinary person who gazes at those who are out of shape or lazy. The so-called "synopticon" refers to those consumers that indulge in the ideal figures produced by the media and constantly conduct various censorship while imitating and chasing these artificial figures, just as many fans of celebrities cannot accept the trivial and secular side of their idols in real life. Specifically, Keep will have a subsection known as "experts" in the "community" section. Various types of fitness experts and scholars have become the center of this community network. The platform will occasionally promote articles about the exercise experiences written by or offline activities hosted by experts. These sports experts will also carefully write "exercise diaries," share their experiences, and set up ideal references for each follower.

Both the fitness experts and novices, regardless of gender or age, are involved in the transparent space of watching and being watched. The liquidity of space aggravates the situation of gazing so that fitness sports may requisition all types of life scenes. Therefore, the space of everyday life is open to the public in the name of fitness.

\footnotetext{
${ }^{6}$ According to the "Sports Enthusiast Behavior Report" released by Keep in 2017, among the more than 130,000 respondents, less than $10 \%$ of them choose "gym, yoga room, and other indoor fitness venues" as their normal fitness venues, while $64.4 \%$ choose "family, dormitory, and other residential areas", and 13.9\% choose "park, playground, and other outdoor venues," and $12 \%$ of users even said they were "working out anytime at anywhere".(http://show.gotokeep.com/event/statisticsreport?utm_medium=Android\&share_ count=1\&utm_source=weibo).
} 
Time strategy: the linear time and rhythmization

Genetics is the core concept in Foucault's analysis of discipline. He uses the school as an example to explain this concept. The student learning process is divided into different stages, which are distinguished by grade assessments. One syllabus is developed for each stage, ranging from simple to complex. Finally, the students are evaluated according to their progress in these series (Foucault 2003:179). In the fitness sports courses Keep provided, this type of "genetic constitution" can also be found, that is, the coding and grading of movements/gestures and the linear time strategy implied in them.

The "Movement repertoire" section of Keep contains all 55 types of movements, ranging from simple to complex. It not only has detailed words, illustrations, and video descriptions for every disassembling step, and the movement details but also "carefully" marks the difficulty rating. For example, the progressive teaching idea, starting from the relatively basic arm and neck movements (as the preparation for complex movements) to the 2-star movement "wide-grip dumbbell and rowing," and then to the 3star movement "barbell bow rowing," is exactly what Foucault called "the genetic constitution." In addition, the movements with different difficulty rankings form the corresponding fitness courses, so the strategy of "genetic constitution" is further embodied in the course settings. For example, "primary fat burning," "primary outdoor comprehensive ability," "segmented running · starter with zero basis," and other similar courses are prepared for novices. "Segmented running · advanced fat burning," "advanced rope skipping HIIT," are advanced courses. Based on completing the above courses, we can consider such advanced courses as "hell burpees challenge" or "Spartan warrior preparation training." The "serialization" of continuous activities makes it possible for power to control time and finally achieve a type of linear time that is continuously integrated, which is a directional and cumulative social time (Foucault 2003:180). You (2003) discusses the influence of the change of the production mode when exploring the origin of modern time (characterized by a linear vector). Because of the emergence of machines, the production cycle of goods is infinitely shortened, and the uncertainty and ambiguity in the previous manual production process are overcome. Therefore, the unidirectional linearity of past-present-future is highlighted in modern people's time consciousness. The training process of people who work out is more like the production process of an industrial good. Every course has strict regulations on movement and time. If the standardization of movement ensures the product's specification and texture (body), the standardization of time transforms the time spent engaging in the fitness sport into a type of "socially necessary labor time." The sports activities, which were previously free and casual, are regulated as the standardized production of the "ideal body." The "lifetime," which was previously complex and changeable, is also replaced by the monotonous and uniform "labor time."

It is worth noting that Keep not only provides guidance on "how to exercise" but also gives clear suggestions on how to rest and relax (such as suggesting a reasonable rest time and the correct warm-up method), aiming to help users avoid sports injuries. Just as machines need regular maintenance, the people who exercise also need proper rest

\footnotetext{
"Wide-grip dumbbell and rowing" is a common movement in back training. This movement has a high demand on the strength of the neck muscle when face down on the ground. In addition, it requires certain upper limb muscle strength, because of the constant holding and lifting of the dumbbell. Therefore, beginners often need to perform upper limb and neck muscle training first to prevent body injury.
} 
as a buffer. Physical energy needs to be accumulated to realize longer working hours. This type of work and leisure time arrangement is a type of "rhythmic" time strategy that advocates leisure and freedom on the surface but belittles them because leisure does not equal willfulness. In his later years, Lefebvre critically reflected on everyday life from the perspective of rhythm. In Lefebvre's view, rhythmization is alienation; rhythmic everyday life is alienated life, while the body is the main bearer of rhythm control (Guan and Zhang 2016). Rhythmization implies homogenization, imposes a universal and monotonous social rhythm on the body, and deprives life of possibility. For society, rhythmization refers to the loss of culture and civilization. "Globalization has unified the rhythm of life across the world, which is arranged according to the rhythm of western "modern time." Even festivals are celebrated in a trend of unification. Christmas and Valentine's day in the West are becoming festivals all over the world" (Wang 2009). This enforcement of rhythm extends from the work/holiday schedule to the exercise/rest schedule. Both fields of the production and consumption are facing the threat of homogenization. In Enjoying It: Candy Crush and Capitalism, Alfie Bowen pointed out that the game served as an invisible ideological tool in the development of late capitalism. After the game's temporary relaxation period, people are willing to return to work again (Shen 2017). In contrast, fitness sport plays an even more prominent role in "helping people return to work." After all, excessive games will cause fatigue, while fitness sports can truly shape a perfect body.

In addition to linear time and rhythmization, the use of little pieces of time is another major strategy of Keep. In its curriculum, it is not difficult to find such courses as "2minute fragmented fat reduction exercise" or "Tabata 4-minute intensive fat burning." When all the little pieces of time are used, the real leisure time disappears and is included in the unified scheduling of linear time. Only the so-called "rest time" (the golden week or the interval in fitness sports) produced by power persists as part of the production.

\section{The knowledge strategy}

In Foucault's analysis of power and knowledge, the subject is the kernel. Certainly, Foucault's intention in the discussion of the subject is to dispel rather than affirm the modern image of the subject with universal rationality. This intention derives from Foucault's reflection on the subject philosophy represented by Descartes. For Descartes, the subject refers to the rational person, who is different from a madman or a sleeping person. Rational people should have rationality, pursue rationality, and arrange their life with rationality (Liu 2005). Therefore, science becomes the Bible of the rational man and the life guide of the subject. For the people who exercise, science could be the source of the function, the significance of fitness sports, or the correct exercise methods. The knowledge discourses of fitness sports spread to the entire society through the mass media and form competition. In brief, the one who could provide more authoritative knowledge to ensure and support the "subject" can take the preemptive opportunity to compete in the fitness market. To some extent, the success of the Keep app ought to attribute to its large-scale adoption of scientific discourse. The storage of fitness knowledge in a software platform significantly exceeds the physical memory of fitness coaches or medical experts. This advantage of software not only 
embodies a large amount of fitness courses but also reflects in the coverage of all the sports knowledge that may be involved in each course. Before the beginning of the course, Keep would introduce the functional types, target user, contraindication, and preparation before training, body reaction, and heat consumption in detail. There are detailed graphic and video descriptions for each action step, details, and precautions during the course. After the course, follow-up courses would be arranged according to the user's feedback.

In addition to the fitness sports courses, Keep has developed different functional sections, such as dietary guidelines, exercise ability tests, and a fitness mall, establishing a large-scale fitness discourse system and, thus, governing every user who pursues the "scientific fitness sport." The rapid development of modern science not only pushes people to the position of historical subjects but also causes a huge rational burden on each individual. Hence, individuals have to learn to give up part of or even the majority of their right to think. The production of knowledge becomes more centralized and invisible. A knowledge community of physiologists, anatomists, and fitness sports experts has been established behind the Keep app.

Although the discourse of fitness sports is of significant integrity, it is not unitary. Unitary means a lack of choice. According to Beck, the "subject" in modern society relies on a wide range of choice opportunities to confirm the realization of "freedom." For example, you can choose to lose fat or increase muscle as the purpose of fitness, exercise the pectoralis major or trapezius muscle, and eat Chinese-style multigrain rice with multicolored beans or a Western-style whole wheat ham sandwich for lunch ${ }^{8}$. Certainly, this type of freedom is challenging because the only choices available are in the classification framework provided by Keep, which is just the extension of anatomy (classification of muscles) or nutrition (classification of food) in fitness discourse. "In a discipline institution, individualization is a kind of "decline." Affected by the power that becomes more invisible and effective, individuals tend to be more individualized" (Foucault 2003:216). Users seem to be free to choose their courses or dietary guidelines and collect fitness information. However, the "possibility and pattern of medicine" (Beck 2004:109) has defined the territory of their freedom at the beginning.

\section{The secrete of self-discipline}

The last section of this paper analyzes the strategic changes of the fitness discipline and provides some discussion of the agency of fitness practitioners in the discipline, from the perspective of time, space, and knowledge. In other words, the power of discipline is not an absolute "domination-dominated" relationship, and fitness practitioners are not just passive bearers. Both the mutual supervision in space (the fitness practitioners become accomplices) and the functioning of the modern view of time and the discourse of fitness knowledge rely on individuals' internalization. However, these do not seem to be convincing to explain the internal motivative mechanism of the practitioners. What meaning-generation process makes them devote themselves to fitness sports?

In fact, in Foucault's theorization of power, the part about "self-discipline" is rather vague. Neither the early discipline theory nor the latter "technologies of the self" are

\footnotetext{
${ }^{8}$ The "dietary guidelines" section of Keep has detailed introductions of these two meals, including the ingredients, cooking procedures, and nutritional values.
} 
consistent with the meaning of self-discipline addressed in this study. The early discipline theory focuses on the coerciveness and externality of power, while the latter "technologies of the self" turns to discuss the practice of freedom. Some scholars have pointed out that Foucault's original intention in writing The History of Sexuality was to follow the example of Discipline and Punishment to explore the operation of power in the field of sexuality. However, Foucault changed his thinking later and began to regard sexuality as one of the most important and convenient areas to explore the technologies of the self (Yang 2000). Therefore, given the ambiguity and transition in Foucault's own theoretical development, this paper attempts to explore the power process hidden behind symbols, values, and meanings from the concept of "self-discipline."

\section{Self-discipline and social distinction}

In addition to Foucault, Elias is another vital figure who has to be mentioned for his observation of the increasing control over the body in modernity. Elias noticed and tried to explain modern society's trend that body-related etiquette norms were constantly changing and becoming increasingly strict. Partially influenced by Weber, he also regarded rationality as an important clue to understand the trend of body civilization. Since the thirteenth century, with the continuous development of the monetary economy and the social division of labor, people's dependence on society has been strengthened in France. Individual action strategies have become cautious and restrained. Elias gradually developed a long-term perspective focusing on the causality chain of the whole society, thus starting his interest in the care and regulation of the body imposed by rational consciousness. From this point of view, it is reasonable to claim that Elias shared many ideas with Foucault.

However, though Elias emphasized the rational tendency of individual behavior and psychology, he had some obvious differences from Weber. Weber regards rationalization as "the sum of all the historical processes that constantly shape social relations and social behaviors," while Elias regards it as just one of the important dimensions of the modernization process (Mo 1994). Less interested in the rationalization of people's behavior and consciousness caused by violent monopoly and social division of labor, Elias pays more attention to the phenomenon of "eating, bathing, and even spitting, which belong to emotional behavior or traditional behavior in Weber's classification" (Song 2013). To generate a more convincing explanation for these physical practices in everyday life, Elias deliberately avoided the thinking disposition of "logicalization of illogical behavior" (Pareto 2007:26) and worked to reveal the original nature of emotional behavior.

In Elias's arguments regarding the sociology of emotion, psychologization is the core concept, which involves sensitivity, shame, and "orientation of othering." To some extent, the increasingly close social structure leads to othering in an individual's actions, especially paying more attention to others' evaluations of the self-body. The development of sensitivity and observation results in a forward move of the threshold value of shame and an enlarging boundary of shameful behavior regarding the body. Consequently, a series of strict body etiquette norms have been gradually established. More importantly, the orientation of othering inevitably engenders an alienation between the individual and the social world. In other words, the more the individual "pays attention 
to" others, the more he will be isolated as "a closed person" by the rational one-way mirror. Paradoxically, the increased social complexity and dependence cause individuals to be unable to live independently outside society. A unique relationship between individuals and society is thus formed, which is both alienated and dependent. The direct consequence is the transformation of the category of fear. The "old" fear of the external natural world and the threat of violence is gradually replaced by the "new" fear of internal competition failure in society. They are "afraid of being fired, being manipulated by the powerful, being hungry and poor," and the most prominent one is "the fear of the decline of social status," which is what Mills called "status panic" (Elias 2013:530, 498; Mills 2012:290). In Elias' empirical studies, in the face of the rapid rising of new social forces, especially the citizen class, the upper class of the European Court had worries and fears about the decline of their social status. In the face of the inevitable and relative loss of political and economic capital, cultural capital remained an important resource for the old nobles to construct a social distinction between the old nobles and the new bourgeois. As a skill that required enough leisure time and cultural background to mold and polish, court etiquette was carefully cultivated by the nobles to establish an insurmountable physical distinction from the later competitors. As Shilling (2011:110) pointed out, since the fourteenth century, it became especially apparent that etiquette's norms were given a strong meaning of symbol struggle in European court life. Individuals had to supervise their appearance and the impression presented to the people around them, to improve their status as much as possible. In this way, the whole society's structural transformation has established a close relationship between body norms and social distinction. The more people want to establish the distinction, the more we need to exert conscious control over the body.

Unlike Foucault, Elias provides new inspirations from the perspective of emotional behavior to comprehend the body's self-control. However, it also raises new questions, that is, whether the differentiation function of the body etiquette to the upper level of the court is helpful to explain the current fitness upsurge in China, especially the remarkable passion and dedication shown by the fitness practitioners?

As mentioned earlier, the significance of transforming the body that the state imposed on the fitness sport in the twentieth century has been gradually weakened since the beginning of the twentyfirst century. In contrast, the penetration of commercialism into the field of fitness is accelerating. From the perspective of society's overall development, the transition of the whole society from a production-oriented society to a consumption-oriented society is behind the growing popularity of fitness sports. When the driving force of social development shifts, the body's role, value, and function begin to change. If the production-oriented society required the accumulation and reproduction of physical capital in a diachronic way, the consumption-oriented society emphasizes the different presentation of physical capital in a synchronic way. To be specific, in the case of fitness sports, compared with the restless pursuits of professional athletes (on behalf of the country or sponsors) in the arena for competition results and physical limits, although people who participate in fitness sports are equally concerned about the output of their physical performance (such as whether they acquire the ideal body shape), their concerns regarding the sport are far more than that. They are also interested in which brand of protein powder to choose, which muscle to exercise first, and which popular fitness sport to master in time. In short, the emerging and 
development of public fitness sports symbolize a gradual change from a physical production practice to a physical consumption practice. If we want to provide a more convincing explanation of the reasons behind this physical asceticism, we cannot neglect this change.

The continuous advancement of the importance of consumption in fitness sports provides the basis for us to enrich the fitness sports research from the perspective of consumption. The significance of consumption in sociology lies precisely in that it is both the raw material for building identity and the embodiment and expression of identity. Consumption and identity are two facets of the same process. It must be emphasized that "identification" involves not only identity but also the realization of difference (Wang 2001; Jenkins 1996). Therefore, under the transformation of consumer culture, fitness sports-a new consumption mode that is different from traditional consumption and emphasizes physical asceticism-possesses the potential to construct a distinction. The consumption theory, represented by Baudrillard's work, provides us with important inspiration and a reference to explore how this potential is realized.

\section{Code manipulation}

The kernel of consumption theory is a type of political analysis that exposes the mechanism of social stratification. Baudrillard insightfully pointed out the changes in this stratification mechanism in the new era. In the past, the pursuit of social status was mainly fulfilled by the absolute possession of things, such as showing off luxury goods. However, it has become inappropriate at present. The society pursues sustainable development, and the process of democratization is advancing, which makes the squandering behavior lose its legitimacy. Therefore, we have entered the era of the "functional society," as Baudrillard termed it. Every commodity must be endowed with a function (use-value) to ensure the legitimacy of the consumption behavior. Consequently, consumers not only identify their position through the price of goods but also through various function codes, to realize the relegitimation of their position.

As one of the most typical commodities in the consumer society, the body is naturally surrounded by various functional codes. As discussed above, beauty and health become everyone's obligations in modern society; thus, the engagement in fitness sports is guaranteed. Through the manipulation of these codes, self-identity is strengthened, and social status is confirmed among practitioners. However, the homelessness of the actual social status fundamentally determines that the process of consumer identification will never end. While continuing to proliferate, the function codes dispel their own significance. The pursuit of beauty involves choosing one's own logo in the existing aesthetic code system: shaping or strengthening? Apollo's belt or firm abs? ${ }^{9}$ Dog waist or swan arm? ${ }^{10}$ Only through this kind of comparative choice can the beauty of practitioners be fully recognized. The "dietary guide" function in Keep could be another example. One hundred twenty-eight types of "healthy" food materials are first listed. Then, these

\footnotetext{
${ }^{9}$ Apollo's belt refers to the contour of the connection between the musculus obliquus externus abdominis and the pelvis. Firm abs refer to the contour of both sides of the connection between the upper part of the sacral vertebra and the lumbar vertebrae. Both of these require long-term exercise to be built in the body. It is an anatomical symbol of beauty and hard work recognized by the fitness practitioner group.

${ }^{10}$ It is similar to Apollo's belt or firm abs as an anatomical sign of targeted strength training.
} 
materials are used to make different types of dishes with various functional divisions, including different scenes, dishes, types, occupations, and seasons, which seems like a dazzling feast of symbols to help users to complete their coding under the legitimate cover of "the discourse of health."

Aerobic or anaerobic exercise? Quick-drying T-shirt, yoga ball, or a foam roller? These are some of the different choices. Apparently, these distinctions give different marks to individuals, while in fact, forcing individuals to recognize this type of coding. The worship of distinction depends on the loss of difference (Baudrillard 2009:72). Rather than providing users with countless recipes, courses, and fitness programs, the fitness app is piling up symbols, which provides many materials for those differentiated functions in fitness sports. Individuals identify their different social statuses in the drastic social transformations through the consumption and manipulation of the body and the symbols attached to it ${ }^{11}$.

\section{Time consumption}

The persistent consolidating of body symbol identification is, on the one hand, objectively derived from various "secondary needs," as well as the basic needs, which are constantly generated by the commodity society to stimulate consumption; on the other hand, subjectively, it is fueled by irrational factors, such as a lack of identity and the panic regarding social status. In the booming economic tide, a problem that has plagued the Western world for centuries has also been imported to China, that is, the anxiety regarding social status (de Botton 2009). Although this anxiety is prevailing in the entire Chinese society, the middle class, as a group with tremendous risks and opportunities, maybe more prominent and, consequently, motivated to pursue social distinction, including that related to the body. This is consistent with some current survey results. Many industry research reports show that students and white-collar groups are the main consumers in the online fitness sports market ${ }^{12}$.

However, the means of consumption are countless. Why can fitness sport gain the attention of the middle class or the potential middle class? In addition to the particular visibility of body consumption, the "time consumption" characteristics of fitness sports constitute another important explanation. The difference between fitness sports and other regular consumption types is that it not only uses traditional currency (to buy equipment and hire a personal coach) but also relies on "time currency." In other words, time plays an extremely important role in the consumption of fitness sports due to the democracy of time and the depreciation rate of time.

From the perspective of democracy, time breaks through the barriers of stratum, culture, and gender and imposes a type of compulsory equality within the entire society. It is true that in many fields of modern society, time can be purchased as a commodity. For instance, in video games, high-consumption players often use the money to compensate for their lack of time investment. However, this set of commercial rules is not effective in fitness sports. For example, the user's updates include the assertion that

\footnotetext{
${ }^{11}$ Baudrillard suggested that people who manipulate code are mainly the middle class. It is the instability of their own social status that makes them particularly interested in floating codes.

${ }^{12}$ Comprehensive Analysis of China's Online Sports and Fitness Market in 2018 (http://www.useit.com.cn/ thread-19588-1-1.html), 2017 Sports and Fitness Crowd Portrait Insight Report (http://www.useit.com.cn/ thread-16234-1-1.html) issued by Beijing TalkingData.
} 
"fitness is not a specific medicine for weight loss, nor is it a body shaping operation; there would be no visible change in 3 or 5 days; at least 3 months are required."13 Excluding special means, such as medicine and fat reduction surgery, fitness is indeed a race without a shortcut for all people. From the perspective of the depreciation speed of time, the "muscle return rate" in the early stage of fitness sports is the highest (called "muscle growth period"), and then, it gradually decreases. When a certain threshold is reached, the time investment is only used to consolidate the existing results (called "platform period"). With the aging of the body, the devaluation of the time currency will be further accelerated.

The time-consuming characteristic of fitness sports adds on a layer of naturality and legitimacy. It echoes how Shilling explains the low tolerance of modern society for an analeptic, i.e., that "natural" athletes show the performance a person can achieve if they submit their bodies to a strictly regulated and effective lifestyle. They are the models of success and the symbols of social mobility. Anyone who works hard enough can achieve such mobility (Shilling 2011:121). For fitness practitioners, although they cannot directly achieve certain occupational mobility through sports, they may experience determining equality guaranteed by time in the process of exploring the possibility of transforming the body naturally without unnatural external force. The significance of time to fitness practitioners is commonly expressed, for example, "follow your own way and principles, even if someone treats you unequally, time will not treat you unequally; the charm of yoga is that insistence leads to success." By "naturalizing" a process (it is believed that as long as time and effort are invested, fitness will eventually succeed) that is essentially guided by technology (i.e., exercising under the guidance of a fitness app), the practicing of fitness sports becomes a new expression of modern democratic politics. However, it may imply a vague understanding of social inequality in a broader sense.

The time investment required by fitness sports makes it a difficult and endless journey, which objectively limits fitness groups' composition. The partial negation of enjoyment and the dependence on the time investment in the fitness sports practice make it a breakthrough opportunity for the middle class to establish their own style and seek a different social status. For the working class, the nature of heavy manual work reduces the possibility of spending more time and physical strength engaging in fitness sports, while for the upper class, their attitude is more casual towards who participates in fitness sports and can stop at any time, ignoring its existence. "The public does not worry about the existence of others, while members of the privileged class are convinced of their existence and may not care about their appearance. The middle class is closely related to appearance. They display the appearance to fulfill its functions-gaining trust and respect-and regard appearance as the guarantee of the products or services they promote, as well as to show their pretentiousness, advance their interests and plans of upward mobility" (Bourdieu 2016: 396). As a result, the middle class becomes the most loyal supporter of the differentiation strategy of fitness sports.

\footnotetext{
${ }^{13}$ The contents quoted here are all from users' updates of the fitness software extracted for this paper. The extraction scheme is in the section of "self-writing" section.
} 


\section{Moral display}

Although the characteristics of "time consumption" provide an objective convenience for the middle class to become involved in fitness sports, to explain fitness practitioners' passion, we need to uncover the intrinsic value of fitness sports. A suite of moral and ethical codes, which are different from the above (health, beauty, etc.) functional codes, is thus proposed.

The suite of complicated steps in furniture maintenance, managing, and cleaning is as follows: "Rendering, polishing, veneering, gilding, waxing, enameling, painting, glazing, shaping, etc." Baudrillard pointed out two characteristics of this type of delicate housework. First, it requires tedious and continuous effort, since the furniture will be covered by dust if it is not cleaned daily, symbolizing the qualities of perseverance and hard work. Second, this tedious effort seems to exceed the apparent necessity and involves a different purpose in piecemeal improvement and excessive decoration. In the subsequent analysis, the origin of the middle-class style, he added as "houses are crowded. Indeed, they often do not have space, but the lack of space brings about an impulse of compensation: the less space is, the more accumulation is". Delicacy became compensation for the destitute in the middle class (Baudrillard 2009:23, 29). A possible case in real life is that there are many spaces in the grand courtyard, while the cramped shed is filled with objects of different sizes and functions. Given such living spaces, how can the space of the body be an exception? In this context, fitness sports have become trapped in the rhetoric of function and morality.

In Keep, what is the first scene that users see when they open the app? A simple sloganself-discipline gives me freedom! This is a well-known slogan of Keep's users, and similar expressions will be interspersed in the intermission parts of various courses. If you chose the course "muscle strengthening training in the family," Schopenhauer's aphorism would appear on the screen when you click pause during the training-"everyone's love or hatred for solitude, that is being alone, is determined by his own intrinsic value." Affirming the value of loneliness, this sentence is a moral appeal for being cautious about solitude, which reminds users to eliminate interference in the training process, be independent, and focus on completing the challenge. As some researchers found in their studies of marathoners, middle-class people, who constitute the majority of runners, generally find that the difficulty in the running process declines, but admit the difficulty of daily perseverance and enjoy the sense of surpassing their past performance in daily practice (Chen 2017).

Compared with other sports, fitness sports and running belong to the same type of independent physical practice. The self-discipline, independence, and other qualities cultivated in independent physical practice are consistent with the life ethics of an "individualized society." Similarly, if you chose the course of "Introduction to abdominal muscle training," the pop-up aphorism will be Garcíam Marquez's sentence-“if God gives me a piece of life, I will simply dress up, lie in the sun, expose my body and soul"-which is intended to remind users that beauty lies in the body rather than in luxury clothes. A simple and natural aesthetic is promoted here. Such moral appeals are scattered throughout the app, and on this basis, users also take the initiative to engage in self-motivation. Either the responsibility ethics of "take care of themselves," such as "the process of people's maturity is the process of learning to get along with themselves," or the eulogy for a certain "natural" value, such as "what decides the clothes you wear is not your wallet, but your body," can be found in the user's updates 
quoted in this paper. These values have nothing to do with truth. They are just values that were popular within a certain period and a certain group. As Baudrillard suggested, the interest of the privileged in the so-called "antique reproduction furniture" was just derived from a negative logic of cultural distinction, i.e., to distinguish the furniture from the "artificial products" popular in the lower classes. The values and functions believed to have absolute truth can only be embodied in class relations and cannot be separated from such relations (Baudrillard 2009:31,33). In other words, the legitimacy of one type of value must be based on the negation of another type of value. The fitness practitioners must confirm their position in the code hierarchy that distinguishes fitness from corpulence. Value symbols, such as "self-discipline" and "nature," must also be compared with "indulgence" and "artificial decoration (make-up, plastic surgery, and luxury clothing)" to obtain the truth. ${ }^{14}$ Through persistent hard work, the practitioners gradually pushed themselves to the positive end of the spectrum of the moral and ethical code. The values of selfdiscipline, perseverance, independence, simplicity, and nature have become noble medals, which are more valuable than the body's health and beauty.

\section{Self-writing}

Given the code manipulation, time consumption, and moral display are the internal processes of self-discipline that support fitness practitioners, and self-writing is the most direct external presentation. What is self-writing? In short, users use a set of functions, such as the "community" and "fitness diary" provided by the app, to record their feelings and experiences in the fitness practice process. The more careful the writing is, the better the effect of self-discipline will be.

Before the discussion of "self-writing," we have to address "writing." In fact, many scholars have discussed writing, especially the invisible relationship between writing and power. Writing involves not only the power to transmit information but also the power to obtain another power by substituting or suppressing information (Greenblatt 1991). In Foucault's work, writing is viewed as a unique discipline strategy. Specific groups, such as guards and doctors, objectify prisoners, and patients through writing. The more complete the prison files and medical records are, the more profound the manipulation of this power is. To some extent, the popularity of the Internet promotes this type of power. Users' physical, geographic, and consumption information is endlessly flowing to software developers through optical cables, and it becomes the new material for writing. Technologies such as big data and cloud computing serve as the new tools for writing. In the "course update" function of Keep, developers can continuously optimize the course difficulty by tracking courses and user training feedback to tailor it to the target population's needs. ${ }^{15}$ The implementation of long-distance and

\footnotetext{
${ }^{14}$ It should be acknowledged that placing self-discipline (relative to indulgence) and natural beauty (relative to artificial beauty) in the code system, to some extent, will mean taking the risk of relativism to comprehend them. After all, the promotion and advancement of fitness sports to people's spiritual quality and physical health is obvious. Hence, it is not so much a criticism of self-discipline or natural beauty as a criticism of its tendency to produce code and truth.

${ }^{15}$ For example, the course "advanced abdominal muscle ripper," which attracted more than 900,000 people, was updated on April 11, 2018. The notice of the update explained that "the course is optimized and adjusted according to continuous tracking of feedback of the course and the training provided by Keepers". The specific updates include "replacement of some movements" and "changes in the number, times and intervals of some movement groups." The purpose of updates is to make the overall difficulty of the course more in line with the needs of the target population and their definition of difficulty.
} 
continuous updating of the fitness curriculum reflects the development of the writing power in the Internet era.

However, more than anything else, the development of technology enables the fitness practitioners to participate in the reproduction of knowledge proactively and generate a large amount of self-writing through the mobile platform, rather than just being satisfied with passively receiving knowledge. In discussing the influence of an expert system in modern society, Giddens pointed out that so-called expertise is always relative. The outsider possesses technical expertise in the customary contact with the abstract system (Yang and Xie 2006:109-110). The emergence of Internet technology accelerates this trend and helps the fitness practitioners transform from the original physical possession to cognitive possession, that is, from practical consciousness to the discourse consciousness. Through the function of "community" in the app, users can publish updated information in various forms, such as text, pictures, and videos, which may summarize a fitness course or a review and reflection on the fitness sports experience.

To better understand the specific content of self-writing and the focus of users' attention, we collect 200 popular updates by refreshing the popular sections at 8:00 p.m. every evening and extracting the top ten system-promoted updates from July 22 to August 10, 2018. 191 pieces of effective updates are obtained after the content review. ${ }^{16}$ The 191 pieces of updates are divided into the following five categories: selfencouragement, reflection, records of the fitness process, knowledge and experience sharing, and teaching videos recorded by practitioners. Among them, updates of knowledge and experience sharing, in particular, symbolize the reproduction of knowledge by users. The publishers are mainly senior practitioners. Among the 45 updates of the knowledge and experience sharing, two are supplementary instructions to the courses provided by the app; three are answers to questions raised by new practitioners; 36 are explanations of fitness knowledge, and the remaining four pieces are reviews and summaries of personal experiences with fitness sports.

In the knowledge and experience sharing of practitioners, much of the content is not provided by the app itself, such as the following: the function and recipe of the "cheat meal;" the improvement of existing recipes-"after several attempts, finally improve the recipe of chicken balls, high protein, low fat, low salt, taste also improved;" an explanation of the "abnormal noise of moving joints"- "if you still feel the pain when joints ring, it may be pathological joint noise;" ten tips for push-ups; the usage of a "healthy abdomen wheel;" the evaluation of "sweaty clothes"- "it is the water, not the fat, that sweaty clothes took away from you." These views of senior practitioners seem bold, novel, conflicting, and mutually corroborating. They seemingly increase the heterogeneity of the discourse of fitness sports provided by the app and destroy its unified and standardized appearance. However, when scrutinizing their content, it does not pose a real challenge to the experts' writing authority. In contrast, the knowledge base of the app itself has been amended and updated to varying degrees by the users' self-writing,

\footnotetext{
${ }^{16}$ Among the 200 user updates, 22 users repeatedly appeared. They published 67 updates in total, but only two of them were duplicated information. In addition, 7 pieces of information were invalid, as they involved travel records and other contents that are not directly related to fitness. Thus, we excluded them and finally obtained 191 valid pieces of information. Forty-one of them were released in video form, accounting for nearly $1 / 5$ of the total. The rest were all in the form of pictures and text.
} 
while the practitioners have achieved deep integration into the discourse system while promoting the growth of the openness of the fitness discourse system.

In addition to discussing different types of difficulties and problems and sharing all types of fitness fashion, practitioners would also write about the existing courses of the app. Although the course introduction of the app itself is quite detailed, some points are still not fully covered. User X explains the app's existing courses by summarizing the advantages and characteristics of the HIIT training as follows: "Keep's HIIT training courses include wakening-up, vitality, fat burning, strengthening, whole body burning." Based on this knowledge extension, "new practitioners remember! HIIT training conforms to the second principle of losing fat, but you must not forget the first principle that $70 \%$ of achievement based on diet and 30\% on a diet." Although the app courses are rich in content, it is inclined to fall into a kind of standard division. Through elaborating the existing courses, the experienced practitioners could reconstruct their own knowledge system while helping the new practitioners comprehend and absorb knowledge. This is especially outstanding in the review and summary of the personal fitness experiences of some of the fitness experts, such as the emphasis on dietary habits-"I will not reduce carbohydrates. I will deliberately reduce the amount of carbohydrates during the period of fat loss, but I cannot stop eating them," the negation of dieting-"I will indeed lose some weight during the period of on a diet, but my basic metabolism will also drop. Once I return to the normal diet, I will rebound," and the choice of fitness time and the usage of time fragments-"there is no time limit except for stretching massage," "strenuous exercise in the evening will hurt your body" or "you can exercise your hips when you go up and downstairs by using your heels."

The fitness practitioners gradually present and textualize the details regarding diet and exercise in the fitness practice through intentional and systematic reviews. Finally, they are summed up as "good living habits" and "following the body's attributes." This writing process, from the body to text, from the concrete to the abstract, from memory extension to reflective extraction, gradually expands the fitness practice beyond the narrow definition of "several sets of practical movements," extends it towards the cultivation of overall living habits, and finally changes it into a lifestyle choice. An excellent article including sports skills, time management, dietary recommendation, or life suggestions may eventually be selected to be included in Keep's "essence" section, which is the highest award for practitioners' self-writing.

In addition to the personalized description of knowledge, the most significant difference distinguishing the self-writing and traditional writing practice is that self-writing can expose the fitness practice's internal dimension. Through constant self-criticism and affirmation, fitness practitioners internalize various value schemas (such as diligence vs. laziness, self-discipline vs. indulgence), which is the process of selflegitimizing the fitness practice, from the initial internal struggle of the fitness practice-"the most difficult time is the beginning of fitness practice"-to learning to psychologically objectify the lazy-"everyone has the lazy devil, and thus, the plan of every day must be completed;" from the self-cultivation of the platform period ${ }^{17}$ - "although no progress is made now and the marks of training are not obvious, ...every effort you

\footnotetext{
${ }^{17}$ After regular and systematic training, the function of each system of the body will be improved from a relatively low level to a higher level. At this point, the body needs a period of time to consolidate the achievements and the fitness effect is not as significant as at the beginning.
} 
put in will not be in vain"- to the later period when you start to enjoy working out- "it seems that your sweat after exercising demonstrates that you haven't wasted the day." Through self-writing, the practitioners not only externalize the cognitive construction process at the mental level and produce writing "full of the essence" but also expose their value attribution and meaning production process at the spiritual level. As the advanced stage of supervision technology, self-writing and self-gazing are different from the supervision of others (omnipticon and synopticon) discussed above, they change the supervision object from the external spatial practice and spatial relationship to the internal cognitive construction and the value shaping process of practitioners so that the object to be gazed eventually extends from the body to the soul.

\section{Conclusion}

Foucault's insightful work on the discipline of the body is still profound today. However, with the advent of the Internet era, the strategy of external discipline has also changed. From the perspective of the fitness practice, the fitness app, which is supported by the new Internet technology, on the one hand, liberates the fitness practitioners from the gym and extends the space of discipline and training to people's private living area by means of the individual's spatial mobility; on the other hand, it advances the "mechanics" and "productivity" of taming of the body to the extreme, in which the coding and grading of fitness movements and courses and the precise control of the time and rhythm in the courses are all perfected by the software depersonalization. The emerging fitness app has compressed fitness practitioners' time and space, making it structured and suffocating.

Furthermore, the app transforms the vague and scattered state of the fitness knowledge of the past (scattered in the real space or network space) and shapes itself as an authoritative knowledge provider through the large-scale expropriation of scientific discourses related to fitness sports. The fitness practitioners have achieved limited freedom through various selections in the "knowledge base." The image of the knowledge subject that is diligent in learning provides an important dimension of rationality for us to understand the self-discipline of practitioners, but it does not suffice to comprehend why practitioners are so devoted to fitness sports. In other words, self-discipline is not confined to the consciousness of rationality.

In Western civilization, Elias found that a change in people's emotions is an important clue to understanding the self-control mechanism of the body. In the transformation from a court society to a bourgeois society in Europe, the aristocracy suffered strong uneasiness and panic regarding their social status since social mobility was accelerating, and the citizen class was rising rapidly. To alleviate the panic and maintain the old decency, they cultivated manners and etiquette (strict physical control) as their important physical capital to distinguish later competitors. The transformation of the social structure established a close relationship between physical norms and social distinction. The more people want to achieve distinction, the more they need to exert conscious control over the body. In this sense, the strict and tedious court etiquette of the old nobles echoed the growing passion of fitness sports practitioners of the middleclass today across time and space. However, there is a significant difference: compared with the former's nearly extravagant use of time and nostalgia for pleasure, the latter chooses to devote themselves to a more rational and restrained life, responding to the 
morality of a new era. The qualities of self-discipline, self-control, and independence cultivated in fitness sports serve as a moral code to distinguish the fitness group from the non-fitness group while responding to the life ethics (taking care of oneself) in the "individualized era."

In the existing research literature of the body, scholars often criticized the uniform and standardized body image (such as slim women and strong men) in the mass media and called it the "body myth" of the consumer society. Today, a new "fitness myth" seems to be brewing. In short, society not only provides an ideal appearance template but also defines the means to achieve this goal. In other words, in the process of reshaping one's body, the process chosen must be healthy and scientific, in which the qualities can be demonstrated, and it must conform to a simple and natural aesthetic orientation; otherwise, it will not only be negated in the aesthetic and healthy code but also in the ethical and moral code.

With the app's assistance, the fitness practitioners first distinguish themselves from the non-fitness group through self-discipline, nature, and other value codes, and then, distinctions are created within the fitness group through various functional codes. Through the differential manipulation of different types of symbols, the practitioners have become the "smartest distinction strategists" in Bourdieu's work, who avoid the futile competition for the possession of external and scarce materials and accumulate the symbol landscape in the body that is more controllable in terms of space and time. As a type of unique consumption practice, fitness sports help the fitness practitioners to reproduce a new type of self-discipline and practice it consciously while pursuing an exclusive position and constructing social distinction.

It is undeniable that since Foucault put forward the power of discipline, many scholars have continued this approach to liberate the body from the object of power domination. Many similar studies are being performed, which raises the following questions: will the discussion of body discipline become a loosely woven criticism in the long run? Would the body just wait for salvation in the abyss of the object and lose all its initiative? For sure, the answer is no. On the one hand, fitness sports have practical value. Many epidemiological surveys show that chronic and degenerative diseases, instead of acute and infectious diseases, are the main health problems of contemporary society, and practicing fitness sports as a preventive means to strengthen the body is welcomed by people. On the other hand, fitness sports practice has its own aesthetic value, and contemporary fitness sports weaken the differences between men and women. Men can try yoga, while women are also keen to participate in strength training. The convergence of fitness methods between men and women has also created a new aesthetic trend-the combination of strength and softness, hardness and bending, muscle, and the thin, which diversifies the beauty of the body. Moreover, just as the criticism of fitness discipline does not damage the fitness sports practice's unique value, the affirmation of the fitness value and fitness practitioners' initiative will not weaken the rationality and profundity of body criticism.

Another issue is worth exploring, that is the field boundary of power discipline in the era of the Internet. Do all the mechanism changes (whether external discipline or selfdiscipline) mentioned in this article only occur in the field of fitness sports? Will history repeat itself? In Foucault's time, discipline power started from prison and spread to the whole society; in the era of the Internet, the branches of power sprawl from the 
cloud data to people's real lives, even to every corner of daily life. On the one hand, power has developed from a micro-distribution to a daily distribution. Although Foucault emphasized the micro-distribution of power from the beginning, it is not difficult to observe that spatial isolation still occurred between different micropower types through his analysis of the military, prisons, schools, and other places. However, with the development of Internet technology, the spatial isolation between different functional fields disappears, forming a trend of mutual penetration. Individuals do not have to go to the gym to engage in fitness sports; learning English is no longer confined to training schools; learning cooking can also be done at home. If learning becomes everyone's obligation in the society of knowledge and individualization, the Internet society further creates a connected field of daily life, weakening the time and spatial limits of learning. When the objective limits of learning are diminishing, human beings eventually stand at the crossing of morality, either diligence or laziness. On the other hand, because of the increasing popularity of mobile software, computer language is gradually replacing daily language as a communication tool, which is not only a perfect way to overcome the emotional obstruction and ignorance fallacy in language expression but is also a cover for the power relationship behind interpersonal communication. When power stands in the cloud of data and overlooks daily life, it gazes at more than fitness practitioners.

\section{Acknowledgements}

N/A

Authors' contributions

Jun Tang designed the study and established the theoretical framework. Zilong Xie conducted research and contributed in analysis. The authors read and approved the final manuscript.

Funding

This study was supported by the BJUT Research Base for Social Governance of Beijing (046000546319557).

Availability of data and materials

The datasets used or analyzed during the current study are available from the corresponding author on reasonable request.

Competing interests

The authors declare they have no competing interests.

Received: 4 August 2020 Accepted: 8 January 2021

Published online: 01 March 2021

References

Baudrillard, J. 2009. Pour une critique de l'économie politique du signe. Xia Ying translated. Nanjing: Nanjing University Press. Beck, U. 2004. Risk Society. He Bowen translated. Nanjing: Yilin Press.

Beck, U., and E. Beck. 2011. Individualization. Li Rongshan, Fan Xuan and Zhang Huiqiang translated. Beijing: Peking University Press.

Bourdieu, P. 2016. La Distinction: Critique sociale du jugement. Liu Hui translated. Beijing: The Commercial Press.

Browning, Gary, Abigail Halcli, and Frank Webster. 2004. The trend of contemporary sociology and social theory. Zhou Yizheng, Jiang Yizhen, Li Zhicheng, Xu Shiwei, he Jingrong, Ji Hao, Yang Huiting, Wang chuanzong, LAN Chenying, Lin Huiping, Lin Yanjun, LV Ziying, Zeng Weikai translated. Taipei: Weber Publication International Ltd..

Bunsell, T. 2013. Strong and hard women: an ethnography of female bodybuilding. London: Routledge.

Chen, Jingshu, and Jian Min. 2014. Body, Power and Sports Participation under the Perspective of Feminism. China Sport Science 7: 12-14.

Chen, Lei. 2012. Body discipline in voluntary abstinence field within micro-power perspective. Master Thesis, Sun Yat-Sen University.

Chen, Xiang. 2017. What caused the popularity of long-distance running and marathons in chinese cities?: on the perspective of anthropology. Master Thesis, Nanjing: Nanjing University.

Cole, C.L., and M. Orlie. 1995. Hybrid athletes, monstrous addicts, and cyborg natures. Journal of Sport History 22 (3): $228-239$.

de Botton, A. 2009. Status anxiety. Chen Guangxing and Nan Zhiguo translated. Shanghai: Shanghai Yiwen Press.

Elias, N. 2013. The civilizing process. Wang Peili and Yuan Zhiying Translated. Shanghai: Shanghai Yiwen Press.

Foucault, M. 1997. Eyes of power on Foucault's analysis of power. Yan Feng translated. Shanghai: Shanghai Renmin Press. 
Foucault, M. 2003. Discipline and punishment. Liu Zhaocheng and Yang Yuanying translated. Beijing: SDX Joint Publishing Company.

Gao, Meiqiong, and Yang Li. 2013. Interpretation of the application of physical "discipline" in the process of modern physical education. Journal of Inner Mongolia University for Nationalities(Natural Sciences) 1: 116-118.

Glassner, B. 1989. Fitness and the postmodern self. Journal of Health and Social Behavior 30 (2): 180-191.

Greenblatt, S. 1991. Marvelous possessions. Chicago: University of Chicago Press.

Guan, Wei, and Xiaona Zhang. 2016. Rhythm analysis of capitalist alienation: reading Lefebvre's rhythm analysis: space, time and daily life. Journal of Dalian Official 4: 12-16.

Huang, Jinlin. 2006. History, body, country -- the formation of body in modern China (1895-1937). Beijing: New Star Press.

Jenkins, R. 1996. Social identity. London: Routledge.

Lin, Xiaoshan. 2013. Reflexive body techniques: a study on auto and body based on grounded theory. Sociological Studies 6: 144-168.

Liu, Tao. 2014. Social media and social production of space: a contemporary interpretation of Michel Foucault's theory of space discipline. Chinese Journal of Journalism \& Communication 5: 48-63.

Liu, Yongmou. 2005. Foucalt's journey of deconstruction of subject. PhD thesis, Beijing: Zhongguo Renmin University.

Mathiesen, T. 1997. The viewer society: Michel Foucault's 'panopticon' revisited. Theoretical Criminology 1 (2): 215-234.

Mauss, M. 2004. Sociology and anthropology. She Biping translated. Shanghai: Shanghai Yiwen Press.

Meng, Xianfeng. 2011. Interpretation on the Foucault's Philosophical theory under the perspective of sport sociology and reflexive significance. Journal of Shenyang Sport University 5: 48-50.

Mills, W. 2012. White collar: the American middle classes. Zhou Xiaohong translated. Nanjing: Nanjing University Press.

Mo, Weimin. 1994. Foucault and critical philosophy of reason. Social Sciences In China 4: 107-117.

Obel, C. 1996. Collapsing gender in competitive bodybuilding researching contradictions and ambiguity in sport. International Review for the Sociology of Sport 31 (2): 185-202.

Pareto, V. 2007. Outline of general sociology. Tian Shigang translated. Beijing: People's Oriental Press.

Pronger, B. 1995. Rendering the body: the implicit lessons of gross anatomy. Quest 47 (4): 427-446.

Rosen, J. 2005. The naked crowd: reclaiming security and freedom in an anxious age. New York: Random House Trade Paperback.

Sault, N. 1994. Many mirrors: body image and social relations. New Brunswick: Rutgers University Press.

Shao Xiaojun. 2014. Body reconstruction and political discipline -- the formation of modern Chinese sports discourse from the perspective of body philosophy, paper presented on International Symposium on physical education and social management.

Shen, Chao. 2017. The value of life time: game capitalism and the extension of working time. Phd thesis, Beijing: Peking University.

Shilling, C. 2011. The body in culture, technology and society. Li Kang translated. Beijing: Peking University Press.

Song, Chong. 2013. A brief analysis on the ideological source of Elias: a conversation with Weber and Freud. Management and Review of Social Sciences 3: 83-89.

Tang, Xiaojun. 2016. Regulation and resistance: a sociological research on children's anti-school culture with fieldwork of three ordinary primary school in N city. Education Research Monthly 1: 30-34.

Turese, N. 1999. Prometheus unbound: the technology of bodybuilding in the nervous age. Past Imperfect 8: 33-61.

Wan, Yichun. 2015. Empowering polarization and alienation: logic demonstration of female sports participation. Sports \& Science 1: 66-70.

Wang, Haiyang. 2009. Time in modernity and reflection on its cultural value. Seeking Truth 4: 28-32.

Wang, Ning. 2001. Consumption and identity. Sociological Research 1: 4-14.

Wen, Jun. 2006. Western Sociological Theory: classical tradition and contemporary turn. Shanghai: Shanghai Renmin Press.

Wolke, D., and M. Sapouna. 2008. Big men feeling small: childhood bullying experience, muscle dysmorphia and other mental health problems in bodybuilders. Psychology of Sport and Exercise 9 (5): 595-604.

Xiong, Huan. 2013. Sporting body theories under feminism perspective. Journal of Beijing Sport University 7: 30-35.

Xiong, Huan, and Aihong Zhang. 2011. Body, society and sport__-sport in the view of western socialist. China Sport Science 6: 81-86.

Xu, Wei. 2013. Research on the theory and practice of humanistic education in college physical education. PhD thesis, Beijing: Beijing Sport University.

Yang, Dachun. 2000. Experience of the body and care of the self: Foucault's philosophy of existence. Journal of Zhejiang University (Humanities and Social Sciences) 4: 116-123.

Yang, Shanhua, and Lizhong Xie. 2006. Western Sociological Theory. Vol. 2. Beijing: Peking University Press.

You, Xilin. 2003. Modernity and time. Academic Monthly 8: 20-33.

Zhang, Han. 2009. Comments on Dobord's Theory of Spectacle Society. Journal of Shandong University (Philosophy and Social Sciences) 3: 126-131.

Zhao, Ben. 2015. Study of semantics of bodybuilding, body fitness and change, problem on the basis of logic. Sichuan Sports Science 4: 23-27.

Zhao, Fangdu. 2010. Body discipline: state power and body in the process of Chinese modernity. PhD thesis, Tianjin: Nankai University.

Zhao, Ge. 2016. Cultural and philosophy research of body and physical exercise phenomenon —- based on consumption theory by Mike Featherstone. China Sport Science 11: 19-30.

Zhong, Jie. 2009. Gymnasium: an analysis of the mechanism of physical discipline. Master Thesis: East China Normal University.

\section{Publisher's Note}

Springer Nature remains neutral with regard to jurisdictional claims in published maps and institutional affiliations. 